\title{
The promises of personalized medicine
}

\author{
Ingolf Cascorbi
}

Received: 30 May 2010 / Accepted: 2 June 2010 / Published online: 19 June 2010

(C) Springer-Verlag 2010

Keywords Individualized medicine - Tailored medicine . Pharmacogenetics · Pharmacogenomics .

Adverse drug events

\section{Introduction}

The concept of personalized medicine is not really new, but it has been receiving increasing attention in recent years in drug regulation and medical guidelines. In an article appearing in this issue of the European Journal of Clinical Pharmacology, Benitez et al. refer to the famous Canadian physician Sir William Osler, whose lifetime work in the 19th century was dedicated towards benefitting the patient as an individual through his goal to make the correct disease diagnosis and the right choice and dose of drugs. However, the introduction of evidence-based medicine and the development of standards of care based on large epidemiological studies of well-defined cohorts significantly altered the strategy to optimize medical practice. By definition, in any analysis of strictly standardized cohorts in clinical trials, individual differences have to be ignored.

With the deciphering of the human genome, high expectations of an individualized approach to medical practice were once again raised, based on the anticipation that information on genetic variability would rapidly contribute to the development of diagnostic tools aimed

\footnotetext{
I. Cascorbi $(\square)$

Institute of Experimental and Clinical Pharmacology,

University Hospital Schleswig-Holstein,

Arnold-Heller-Str. 3, Bldg. 30,

24105 Kiel, Germany

e-mail: cascorbi@pharmakologie.uni-kiel.de
}

at avoiding drug side effects or identifying genetic markers that would predict therapy response. As a consequence, the discipline of pharmacogenetics developed rapidly and contributed significantly to an increased understanding of interindividual differences in drug therapy response, particularly in pharmacokinetics and, to some extent, pharmacodynamics. This development has caused Benitez et al. to raise the question of whether therapeutic drug (TDM) monitoring, an accepted tool to monitor drug bioavailability, has been replaced completely by pharmacogenetic testing.

With regret, these early expectations of being able to predict drug therapy response solely by identifying genetic markers have been exaggerated in some cases and remained unfulfilled in others. Therefore, the answer to the question may be simple: genetics cannot completely predict an individual's phenotype due to the additional contribution of epigenetic, endogenous and - last but not least—behavioural environmental factors. However, pharmacogenetics is able to add important information in many cases where TDM is inappropriate or not sufficient. In particular, pharmacogenomics has become indispensable in the treatment of malignant diseases, and there is increasing evidence of its value in many other areas of medicine.

\section{Definition of personal medicine}

The "Personalized Medicine Coalition" formed in 2005 [1] defines personalized medicine as "the application of genomic and molecular data to better target the delivery of health care, facilitate the discovery and clinical testing of new products, and help determine a person's predisposition to a particular disease or condition." Personalized medicine 
reflects different levels of variability, as can be exemplified best in the field oncology: (1) definition of disease on the molecular level, such as different types of leukaemia or over-expression of the her $2 /$ neu-receptor in breast cancer requiring specific therapies (e.g. application of trastuzumab); (2) somatic mutations occurring in tumour tissuefor example, cetuximab should only be used in colorectal cancer patients with the wildtype KRAS; (3) germline mutations influencing the pharmacokinetics of various drug, such as azathioprine, in childhood leukaemia or inflammatory bowel disease due to variants in UGT1A1 leading to a pronounced danger of myelotoxicity; (4) drug hypersensitivity due to variants in the HLA-system, exemplified in the case of the protease inhibitor abacavir; (5) epigenetic factors controlling gene expression; (6) environmental and behavioural factors. Therefore, personalized medicine encompasses more factors of variability than only genetics, which is most relevant to pharmacogenetics or pharmacogenomics.

Nevertheless, the significant value of pharmacogenetics is based on the fact that genetic material provides constant life-long information and is easy accessible. It was anticipated that research in pharmacogenetics would offer the opportunity to identify new drug targets and to adjust the individual required dosage of drugs already approved for clinical use $[6,13]$.

\section{Application of personal medicine in clinical practice}

Can the promises of personalized medicine be fulfilled? Clinical pharmacologists have made major contributions to personalized medicine in terms of pharmacogenetics or careful observations of plasma drug concentrations. However, as outlined above, pharmacogenetics or TDM represent only parts personalized medicine. Therefore, I like to highlight three clinical indications for which the genetic make-up of the patient has been shown to affect the pharmacokinetics and dynamics of the drug therapy, ultimately leading to regulatory authorities changing drug guidelines and drug labels.

Hypersensitivity Pharmacogenetics may help to avoid severe adverse effects, such as skin hypersensitivity, as best exemplified for abacavir. Drug hypersensitivity can be defined as an inappropriate immune response that is associated with some degree of genetic background, mostly identified in the major histocompatibility complex [25]. This response cannot be predicted from the structure of the compound and is dose-independent. In $5 \%$ of abcavirtreated human immunodeficiency virus (HIV) patients, immunologically mediated severe skin damage occurs. In most cases, such a risk-benefit ratio is considered to be unacceptable by regulatory authorities, leading to withdrawal of the drug. In studies among Caucasians, 48-61\% of patients experiencing this severe side effect had the MHC marker HLA-B*5701, while none of the HLAB*5701-negative patients developed an immunological confirmed hypersensitivity reaction [17]. This risk-benefit ratio led regulatory agencies to change the abacavir drug labels in the USA and Europe, and HLA-B*5701 typing is now obligatory before abacavir therapy is launched. The change to the label has not only led to a lower frequency of hypersensitivity reactions, but also to increased use of the drug and, consequently, increasing sales rates, a major benefit to the manufacturer. Abacavir genetics-driven personal treatment is one of the best examples of personalized medicine outside the area of oncology.

Anticoagulation Thorough genome-wide association studies have revealed genetic markers of coronary artery disease with an over-all odds ratio of 1.2-1.3, thus providing some insight into the aetiology of this disease, but they are not currently in use for the selection or dose adaption in preventive medication [26]. However, in the prevention of thrombotic events with atrial fibrillation, the polymorphic cytochrome P450 2C9 (CYP2C9) protein is accepted as the rate-limiting drug-metabolizing enzyme of warfarin clearance and, to less extent, also to the clearance of alternative vitamin $\mathrm{K}$ antagonists, such as acenocoumarol and phenprocoumon. A prospective study addressing the question of whether a priori knowledge of CYP2C9 genotype may improve warfarin therapy demonstrated that patients who were treated applying a CYP2C9 genotype-adjusted algorithm reached a significantly earlier stable anticoagulation state and experienced less minor bleeding [3] than those who were not. Moreover, subjects who are carriers of variants in the vitamin $\mathrm{K}$ epoxide reductase complex, subunit 1 (VKORC1) gene require significantly higher warfarin doses than usually recommended $[5,30]$. In order to estimate appropriate warfarin dosing, algorithms based on both clinical and genetic data obtained from a broad population base have been calculated in a large cohort, thereby achieving a better prediction of subjects requiring lower doses of warfarin for therapeutic anticoagulation [15]. These results were acknowledged by the Federal Drug Administration (FDA) in 2007 and updated in 2010, with the result that the drug label for warfarin was changed. This labeling change highlights the opportunity for healthcare providers to use genetic tests to improve their initial estimate of what is a reasonable warfarin dose for individual patients - although the test is not mandatory.

Oncology The best evidence of successful applications of personalized genetically based medicine has been found in the field of oncology. Our increasing knowledge of the 
etiology and molecular character of different types of malignancies as well as a better understanding of the mode of action and pharmacokinetics of anticancer drugs has led to a revolution in drug therapy regimens. In particular, the treatment of acute lymphoblastic leukemia has been substantially improved through the application of modern molecular diagnostics and the optimization of existing therapy regimens [9]. The consequent use of genomic information, however, has also led to a further significant step forward in terms of lower side effects and optimization of the clinical outcome [22]. Such information is used in designing treatments with anticancer drugs having a narrow therapeutic index. Genetic testing is recommended (but not required) for irinotecan, which is conjugated by the polymorphic UDPglucuronosyltransferase 1 [11], and for azathioprine, detoxified by thiopurine methyltransferase [27].

As mentioned above, in terms of genetic information, it is important to distinguish between germline and somatic mutations and chromosomal aberrations. For example, imatinib, targeted towards the characteristic BCR-ABL fusion protein, which is present in Philadelphia chromosomepositive cells, has become the standard therapy for chronic myeloic leukaemia (CML) [23]. Moreover, trastuzumab is only effective in breast cancer patients, exhibiting overexpression of the her $2 /$ neu receptor that mediates a broad cascade of tumour-promoting signals and significantly lowers the overall survival of the patient [24]. This and further information are considered in the current guidelines, and regulatory authorities have acknowledged a number of drugrelated genomic factors in tumours requiring specific testing prior to the selection of the appropriate therapy regimen
(Table 1). These approaches match perfectly the goal of personalized medicine.

\section{Uncertain role of pharmacogenetics in personalized medicine}

A large body of data are available from studies showing a strong correlation between genetic status and both pharmacokinetics and pharmacodynamics. However, results from studies on the contribution of genetics to therapeutic outcome have often been found to be non-reproducible, or data from prospective studies are lacking, as exemplified in the field of psychiatry. Antidepressant and antipsychotic drugs are widely subject to TDM since there is a large interindividual variability in plasma concentrations, partly due to the strong effect of the patient's genetic background based on individually different metabolic rates of cytochrome P4502D6 [14]. It was therefore anticipated that CYP2D6 would have severe consequences on the side effects and clinical outcomes of patients being treated without consideration of the metabolizer status. There is a large body of literature describing the consequences of CYP2D6 genotypes on the pharmacokinetics of antidepressants and neuroleptics. The clearance of most tricyclics evidently depend on CYP2D6 polymorphisms, and some studies have shown an overrepresentation of CYP2D6 poor metabolizers among patients reporting adverse events $[16,29]$ or of ultra-rapid metabolizers in cases in which the drug therapy has been ineffective [29, 31]. The kinetics

Table 1 Valid genomic biomarkers in the context of approved drug labels

\begin{tabular}{|c|c|c|c|}
\hline Indication & $\begin{array}{l}\text { Drugs for which patient testing } \\
\text { is required before prescription }\end{array}$ & $\begin{array}{l}\text { Drugs for which } \\
\text { patient testing is } \\
\text { recommended }\end{array}$ & $\begin{array}{l}\text { Drugs for which } \\
\text { pharmacogenomic } \\
\text { information is available }\end{array}$ \\
\hline Anticoagulation & & Warfarin & \\
\hline Antithrombosis & & & Clopidogrel, prasugrel \\
\hline Epilepsy, neuropathic pain & $\begin{array}{l}\text { Carbamazepine }^{\mathrm{a}} \text { (in some } \\
\text { areas of Southeast Asia)) }\end{array}$ & & \\
\hline $\begin{array}{l}\text { Human immunodeficiency } \\
\text { virusV }\end{array}$ & Abacavir, maraviroc & & \\
\hline Infections & & & $\begin{array}{l}\text { Voriconazole, isoniazid, } \\
\text { primaquine }\end{array}$ \\
\hline Inflammation & & & Celecoxib \\
\hline Lipid disorders & & & Atorvastatin \\
\hline Oncology & $\begin{array}{l}\text { Arsenic trioxide, busulfan, } \\
\text { cetuximab, dasatinib, erlotinib } \\
\text { gefitinib, imatinib lapatinib, } \\
\text { nilotinib panitumumab, } \\
\text { rasburicase, trastuzumab }\end{array}$ & $\begin{array}{l}\text { Irinotecan, azathioprine, } \\
\text { tretinoin }\end{array}$ & \\
\hline Psychiatry & & & Atomoxetine, fluoxetine \\
\hline
\end{tabular}

${ }^{\text {a }}$ According to product information released by the FDA 03/15/2010 
of specific serotonin reuptake inhibitors is less dependent on CYP2D6, but these drugs are particularly strong inhibitors of CYP2D6. A consensus on dose recommendations of antidepressants according to the CYP2D6 and CYP2C19 genotype was published in 2001 [12], and in 2005 a diagnostic tool (Roche Amplichip CYP450 test) was approved by the FDA as the first pharmacogenetic test to genotype genetic variants affecting the metabolism of psychotropic drugs. However, although genotypedependent dose recommendations have been suggested, this knowledge has not yet been translated into clinical practice, and concern has been expressed as to whether any genotype-related adjustment of dosage can improve the clinical outcome in terms of clear psychometric measures or if relevant adverse events can be prevented [14]. There have been large retrospective trials on the susceptibility of depression and outcome measures, also in relation to genetic variants in the serotoninergic system [28]; however, no genetic trait has been accepted as yet as a useful predictor of the therapeutic outcome in daily practice. As highlighted perfectly by Benitez et al., TDM of psychotropic drugs does not predict the clinical efficacy, although it does help to control compliance and toxicity. Consequently, taking into account the possibility of genetic variants contributing to pharmacokinetics may help the medical practitioner to determine the most appropriate dose to lower interindividual variability of plasma concentrations. There is a need to develop better algorithms in which gene-directed dosing are considered in addition to other physiological, behavioural and psychopathological parameters. The current approach to personalized medicine in psychiatry is relatively non-systematic way-sometimes based on TDM and only rarely based on genetic information. However, genome-wide association studies (GWAS) that consider well-defined psychometric phenotypes may provide further insight into the etiology of the disease and also help to identify genetic markers of treatment outcome [2].

Active discussions in the field of cardiology have also arisen with the observation that the pro-drug clopidogrel, which is used for platelet aggregation prophylaxis after coronary stent-implantation, among other applications, is activated by polymorphic CYP2C19-mediated oxidation and subsequent hydrolysis to its active derivative. Genotype-dependent clinical consequences for the risk of stent thrombosis have been shown recently [19], and elevated enzyme activity in carriers of CYP2C19*17 is now known to be significantly associated with enhanced response to clopidogrel and a threefold increased bleeding risk. However, the CYP2C19 phenotype does not only depend on the genetic constitution of the patient; the activity of the enzyme can be inhibited by other drugs, such as the proton pump inhibitor omeprazol. Indeed, the consequences of drug interactions have been demonstrated in a large cohort of acute coronary syndrome patients receiving proton pump inhibitors concomitantly with clopidogrel [10]. Therefore, individual manifestations of clopidogrel resistance can be explained by both pharmacogenetics and drug interactions. Pharmacogenetic data is currently mentioned in the label, but it has only an informative character. In cases of clopidogrel resistance, the novel drug prasugrel an be used as an alternative as it is not significantly affected by CYP2C19 activity [20].

\section{Conclusion}

Coming back to TDM, this sometimes dismissed diagnostic tool is still of high value whenever pharmacotherapy has to be controlled for compliance, the occurrence of side effects or treatment failure. It remains, in my opinion, an indispensable component of personalized medicine. However, as mentioned above, personalized medicine is widely considered to be the individualized use of genomic and molecular data, even though pharmacogenetics cannot completely replace TDM as an important diagnostic tool in the control of antidepressive, antipsychotic, anti-infective or immunosuppressant treatments.

Personalized medicine as defined by only its genomic and molecular components, however, is rapidly assuming an important role in various field of medicine, particularly in oncology, and has contributed to therapy regimens being clearly based on the characterization of genomic information. The presence of genomic markers, such as mutations in epidermal growth regulator factor (EGFR) or KRAS, may be decisive for the successful treatment of solid and non-solid malignancies, and such information is being increasingly recognized and implemented by regulatory authorities. There is also increasing evidence for the application of personalized medicine in immunological and/or inflammatory diseases [21]. Personalized medicine is actually becoming accepted in oncology much more quickly due both to the diversity and potentially lethal character of the disease and to the narrow therapeutic index and low benefit-risk ratio of the drugs used. Moreover, our increasing knowledge in epigenetics has led to a better understanding of the molecular background of tumour initiation and progression, particularly in haematological neoplasms [18].

Regulatory authorities themselves have encouraged further clinical research on the practical relevance of pharmacogenomics [8]. As a consequence, a number of questions are emerging: Will the determination of genetic data always be accepted by physicians and patients? Who is authorized for genetic counselling and when is it necessary [7]? Is personalized medicine more cost-effective [4]? Personalized medicine is not necessarily a contradiction to 
standardized therapy-it is evidence-based medicine using genomic and molecular data to better target the delivery of healthcare to individuals. Therefore, it should be applied whenever evidence is available. However, to avoid hollow promises, more robust clinical prospective studies have to be performed to evaluate the cost-benefit ratio in terms of an individual patient's advantage.

\section{References}

1. Abrahams E, Ginsburg GS, Silver M (2005) The Personalized Medicine Coalition: goals and strategies. Am J Pharmacogenomics 5:345-355

2. Butler AW, Cohen-Woods S, Farmer A, McGuffin P, Lewis CM (2010) Integrating phenotypic data for depression. J Integr Bioinform 7. doi:10.2390/biecoll-jib-2010-136

3. Caraco Y, Blotnick S, Muszkat M (2008) CYP2C9 genotypeguided warfarin prescribing enhances the efficacy and safety of anticoagulation: a prospective randomized controlled study. Clin Pharmacol Ther 83:460-470

4. Collins CD, Purohit S, Podolsky RH, Zhao HS, Schatz D, Eckenrode SE, Yang P, Hopkins D, Muir A, Hoffman M, McIndoe RA, Rewers M, She JX (2006) The application of genomic and proteomic technologies in predictive, preventive and personalized medicine. Vascul Pharmacol 45:258-267

5. D'Andrea G, D'Ambrosio RL, Di Perna P, Chetta M, Santacroce R, Brancaccio V, Grandone E, Margaglione M (2005) A polymorphism in the VKORC1 gene is associated with an interindividual variability in the dose-anticoagulant effect of warfarin. Blood 105:645-649

6. Eichelbaum M, Ingelman-Sundberg M, Evans WE (2006) Pharmacogenomics and individualized drug therapy. Annu Rev Med 57:119-137

7. Fleeman N, Dickson R (2009) Providing patients with information on pharmacogenetic testing. Nurs Stand 23:46-48

8. Frueh FW (2010) Real-world clinical effectiveness, regulatory transparency and payer coverage: three ingredients for translating pharmacogenomics into clinical practice. Pharmacogenomics 11:657-660

9. Gerr H, Zimmermann M, Schrappe M, Dworzak M, Ludwig WD, Bradtke J, Moericke A, Schabath R, Creutzig U, Reinhardt D (2010) Acute leukaemias of ambiguous lineage in children: characterization, prognosis and therapy recommendations. $\mathrm{Br} \mathrm{J}$ Haematol 149:84-92

10. Ho PM, Maddox TM, Wang L, Fihn SD, Jesse RL, Peterson ED, Rumsfeld JS (2009) Risk of adverse outcomes associated with concomitant use of clopidogrel and proton pump inhibitors following acute coronary syndrome. JAMA 301:937-944

11. Hoskins JM, Goldberg RM, Qu P, Ibrahim JG, McLeod HL (2007) UGT1A1*28 genotype and irinotecan-induced neutropenia: dose matters. J Natl Cancer Inst 99:1290-1295

12. Kirchheiner J, Brosen K, Dahl ML, Gram LF, Kasper S, Roots I, Sjoqvist F, Spina E, Brockmoller J (2001) CYP2D6 and CYP2C19 genotype-based dose recommendations for antidepressants: a first step towards subpopulation-specific dosages. Acta Psychiatr Scand 104:173-192

13. Kirchheiner J, Fuhr U, Brockmoller J (2005) Pharmacogeneticsbased therapeutic recommendations-ready for clinical practice? Nat Rev Drug Discov 4:639-647

14. Kirchheiner J, Seeringer A, Viviani R (2010) Pharmacogenetics in psychiatry - a useful clinical tool or wishful thinking for the future? Curr Pharm Des 16:136-44
15. Klein TE, Altman RB, Eriksson N, Gage BF, Kimmel SE, Lee MT, Limdi NA, Page D, Roden DM, Wagner MJ, Caldwell MD, Johnson JA (2009) Estimation of the warfarin dose with clinical and pharmacogenetic data. N Engl J Med 360:753-764

16. Laika B, Leucht S, Heres S, Steimer W (2009) Intermediate metabolizer: increased side effects in psychoactive drug therapy. The key to cost-effectiveness of pretreatment CYP2D6 screening? Pharmacogenomics J 9:395-403

17. Mallal S, Phillips E, Carosi G, Molina JM, Workman C, Tomazic J, Jagel-Guedes E, Rugina S, Kozyrev O, Cid JF, Hay P, Nolan D, Hughes S, Hughes A, Ryan S, Fitch N, Thorborn D, Benbow A (2008) HLA-B*5701 screening for hypersensitivity to abacavir. N Engl J Med 358:568-579

18. Martin-Subero JI, Ammerpohl O, Bibikova M, WickhamGarcia E, Agirre X, Alvarez S, Bruggemann M, Bug S, Calasanz MJ, Deckert M, Dreyling M, Du MQ, Durig J, Dyer MJ, Fan JB, Gesk S, Hansmann ML, Harder L, Hartmann S, Klapper W, Kuppers R, Montesinos-Rongen M, Nagel I, Pott C, Richter J, Roman-Gomez J, Seifert M, Stein H, Suela J, Trumper L, Vater I, Prosper F, Haferlach C, Cruz CJ, Siebert R (2009) A comprehensive microarray-based DNA methylation study of 367 hematological neoplasms. PLoS ONE 4: e6986

19. Mega JL, Close SL, Wiviott SD, Shen L, Hockett RD, Brandt JT, Walker JR, Antman EM, Macias W, Braunwald E, Sabatine MS (2009) Cytochrome p-450 polymorphisms and response to clopidogrel. N Engl J Med 360:354-362

20. Mega JL, Close SL, Wiviott SD, Shen L, Hockett RD, Brandt JT, Walker JR, Antman EM, Macias WL, Braunwald E, Sabatine MS (2009) Cytochrome P450 genetic polymorphisms and the response to prasugrel: relationship to pharmacokinetic, pharmacodynamic, and clinical outcomes. Circulation 119:2553-2560

21. Mesko B, Poliska S, Szegedi A, Szekanecz Z, Palatka K, Papp M, Nagy L (2010) Peripheral blood gene expression patterns discriminate among chronic inflammatory diseases and healthy controls and identify novel targets. BMC Med Genomics 3:15

22. Moricke A, Zimmermann M, Reiter A, Henze G, Schrauder A, Gadner H, Ludwig WD, Ritter J, Harbott J, Mann G, Klingebiel T, Zintl F, Niemeyer C, Kremens B, Niggli F, Niethammer D, Welte K, Stanulla M, Odenwald E, Riehm H, Schrappe M (2010) Longterm results of five consecutive trials in childhood acute lymphoblastic leukemia performed by the ALL-BFM study group from 1981 to 2000. Leukemia 24:265-284

23. Muller MC, Cross NC, Erben P, Schenk T, Hanfstein B, Ernst T, Hehlmann R, Branford S, Saglio G, Hochhaus A (2009) Harmonization of molecular monitoring of CML therapy in Europe. Leukemia 23:1957-1963

24. Nanda R (2007) Targeting the human epidermal growth factor receptor 2 (HER2) in the treatment of breast cancer: recent advances and future directions. Rev Recent Clin Trials 2:111116

25. Pirmohamed M (2006) Genetic factors in the predisposition to drug-induced hypersensitivity reactions. AAPS J 8:E20-E26

26. Samani NJ, Deloukas P, Erdmann J, Hengstenberg C, Kuulasmaa K, McGinnis R, Schunkert H, Soranzo N, Thompson J, Tiret L, Ziegler A (2009) Large scale association analysis of novel genetic loci for coronary artery disease. Arterioscler Thromb Vasc Biol 29:774-780

27. Schaeffeler E, Fischer C, Brockmeier D, Wernet D, Moerike K, Eichelbaum M, Zanger UM, Schwab M (2004) Comprehensive analysis of thiopurine S-methyltransferase phenotype-genotype correlation in a large population of German-Caucasians and identification of novel TPMT variants. Pharmacogenetics $14: 407-417$ 
28. Serretti A, Chiesa A, Calati R, Perna G, Bellodi L, De Ronchi D (2009) Common genetic, clinical, demographic and psychosocial predictors of response to pharmacotherapy in mood and anxiety disorders. Int Clin Psychopharmacol 24:1-18

29. Sjoqvist F, Eliasson E (2007) The convergence of conventional therapeutic drug monitoring and pharmacogenetic testing in personalized medicine: focus on antidepressants. Clin Pharmacol Ther 81:899-902
30. Yuan HY, Chen JJ, Lee MT, Wung JC, Chen YF, Charng MJ, Lu MJ, Hung CR, Wei CY, Chen CH, Wu JY, Chen YT (2005) A novel functional VKORC1 promoter polymorphism is associated with inter-individual and inter-ethnic differences in warfarin sensitivity. Hum Mol Genet 14:1745-1751

31. Zackrisson AL, Lindblom B, Ahlner J (2009) High frequency of occurrence of CYP2D6 gene duplication/multiduplication indicating ultrarapid metabolism among suicide cases. Clin Pharmacol Ther. doi:10.1038/clpt.2009.216 